\title{
Frozen shoulder and risk of cancer: a population-based cohort study
}

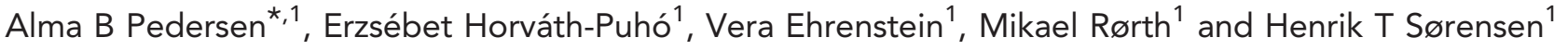 \\ ${ }^{1}$ Department of Clinical Epidemiology, Aarhus University Hospital, Aarhus, Olof Palmes Alle 43-45, Aarhus N 8200, Denmark
}

Background: Frozen shoulder might be a complication or a presenting symptom of cancer. We examined the risk of a cancer diagnosis after an incident diagnosis of frozen shoulder.

Methods: We used prospectively collected data from Danish registries to identify patients with frozen shoulder during 1995-2013 and followed them for the development of cancer.

Results: We observed 2572 incident cancers among 29098 frozen shoulder patients. The expected number of incident cancers in the general population was 2434 . The 6-month cumulative incidence of any cancer was $0.70 \%$, corresponding to a standardised incidence ratio (SIR) of 1.38 (95\% confidence interval (CI): 1.19-1.58). Risk increases were highest for lung cancer (SIR $=2.19,95 \% \mathrm{Cl}$ : 1.48-3.13), breast cancer ( $\mathrm{SIR}=1.51,95 \% \mathrm{Cl}: 1.02-2.15)$, and non-Hodgkin's lymphoma ( $\mathrm{SIR}=2.28,95 \% \mathrm{Cl}: 1.09-4.20)$. The cumulative incidence of any cancer during the remainder of follow-up ( $>6$ months to a maximum 18.9 years) was $24.8 \%$ with an SIR of 1.04 (95\% Cl: 1.00-1.08).

Conclusions: Frozen shoulder might be an early predictor for a subsequent cancer diagnosis.

Frozen shoulder, also called adhesive capsulitis, is characterised by stiffness and pain in the shoulder joint due to inflammation of the synovial lining and capsule (Zuckerman and Rokito, 2011). The aetiology of frozen shoulder is not fully understood. It can develop after a shoulder has been immobilised (Robinson et al, 2012). An increased incidence of frozen shoulder was observed in diabetes vs non-diabetes patients (1.2 vs 0.9\%; Huang et al, 2013) and in patients with diseases such as thyroid and Parkinson's disease, chronic obstructive pulmonary disease (COPD), and myocardial infarction (MI) (Wohlgethan, 1987; Chang et al, 2015). Frozen shoulder can last for up to 3 years, and resolves spontaneously in most cases (Eljabu et al, 2016).

Frozen shoulder can be a musculoskeletal manifesting of solid tumours and haematological malignancies (Ashour et al, 1997; Latham et al, 2001; Singh et al, 2005; Gheita et al, 2010), and may also represent a misdiagnosed shoulder tumour (Demaziere and Wiley, 1991; Robinson et al, 2003; Sano et al, 2010). In addition, frozen shoulder is a frequent complication after mastectomy due to breast cancer (Wedgwood and Benson, 1992; Cheville and Tchou, 2007).

Thus, there is some clinical evidence, based on case reports and small cross-sectional studies, that patients with malignancies are at increased risk of frozen shoulder. We examined the association between frozen shoulder diagnosis and subsequent risk of cancer using linked data from Danish population registries.

\section{MATERIALS AND METHODS}

We conducted this study in Denmark, using prospectively collected data from the Danish Civil Registration System (DCRS) and the Danish National Patient Registry (DNPR). The DCRS has recorded date of birth, sex, and vital status of all Danish residents since 1968, and a unique civil registration number, which permits unambiguous linkage across all Danish registries (Schmidt et al, 2014). The DNPR contains information on all hospitalisations since 1977, as well as outpatient hospital clinic contacts since 1995 (Schmidt et al, 2015). We used the DNPR to establish a cohort of all patients with a first-time hospital-based diagnosis of frozen shoulder from 1 January 1995 to 30 November 2013. Both primary and secondary diagnoses were included. The DNPR also was used to obtain data on history of diabetes mellitus (DM), COPD, MI, thyroid disorders, and Parkinson's disease (Supplementary Material). To assess cancer outcomes, data from the frozen shoulder cohort were linked to the Danish Cancer Registry (DCR) (Gjerstorff, 2011),

*Correspondence: Dr AB Pedersen; E-mail: abp@clin.au.dk

Received 6 January 2017; revised 24 April 2017; accepted 27 April 2017; published online 18 May 2017

(C) 2017 Cancer Research UK. All rights reserved 0007 - 0920/17 
which contains information on all incident primary cancer cases in Denmark since 1943. Patients diagnosed with cancer before their frozen shoulder were excluded, as were patients with a frozen shoulder diagnosis prior to 1995.

All patients were followed from the date of hospital admission or date of a hospital outpatient clinic consultation for a frozen shoulder until a cancer diagnosis, emigration, death, or the end of the observation period (30 November 2013), whichever occurred first. Risk of cancer was examined during two periods of follow-up: $0-\leqslant 6$ months and $>6$ months after a frozen shoulder diagnosis. We calculated incidence rates of cancer per 1000 person-years and standardised incidence ratios (SIRs) as the ratio of observed to expected numbers of cancer events in the general population. We computed 95\% confidence intervals (CIs), assuming that the observed number of cancer events followed a Poisson distribution. Whenever the observed number of events was fewer than 10, exact 95\% CIs were used; otherwise Byar's approximation was used (Rothman and Boice, 1982). Standardised incidence rates were calculated overall for any cancer, for selected cancer types, and by stage (Balch et al, 2009). We also computed the cumulative incidence of cancer in patients with a frozen shoulder diagnosis, treating death as a competing risk.

\section{RESULTS}

From 1 January 1995 to 30 November 2013, we identified 29098 patients diagnosed with a frozen shoulder, contributing 182888 person-years of time at risk. Median follow-up time was 5.0 years (lower quartile: 2.2 years; upper quartile: 9.3 years). Median age at frozen shoulder diagnosis was 53 years (lower quartile: 46 years; upper quartile: 61 years), and $56 \%$ of patients were female.

During $0-\leqslant 6$ months following their frozen shoulder diagnosis, 198 patients received a diagnosis of any cancer. The corresponding cumulative incidence was $0.70 \%$, and the SIR was 1.38 (95\% CI: 1.19-1.58). Standardised incidence rates were similarly increased in men and in women. In addition, increased risk of any cancer was seen among patients aged 40-49 years and those older than 60 years, as well as among patients diagnosed with a frozen shoulder during 1995-2004, but not during 2005-2013 (Table 1). An increased risk of cancer was observed among cohort members without a history of MI, COPD, DM, or thyroid/Parkinson's disease (Table 1). Risk of cancer diagnosis was further increased in patients with many hospital contacts during follow-up period (Table 1). Among 133 patients with available data on cancer stage, $61 \%$ were diagnosed with stage I or II cancer within first 6 months of frozen shoulder diagnosis. During the first 6 months following a frozen shoulder diagnosis, increased SIRs were observed for the following site-specific cancers: lung (SIR 2.19, 95\% CI: 1.48-3.13), breast (SIR 1.51, 94\% CI: 1.02-2.15), and non-Hodgkin's malignant lymphoma (SIR 2.28, 95\% CI: 1.09-4.20; Table 2).

More than 6 months and up to 18.9 years following a frozen shoulder diagnosis, 2374 patients were diagnosed with any cancer. The cumulative incidence was $24.8 \%$ and the SIR was 1.04 (95\% CI: 1.00-1.08; Table 1). Median follow-up time was 4.9 years (lower quartile 2.1 years; upper quartile 9.2 years). Among specific

Table 1. SIRs of any cancer in diagnosed patients with a prior first-time hospital-based diagnosis of frozen shoulder, stratified by patient characteristics and follow-up periods, Denmark, 1995-2013

\begin{tabular}{|c|c|c|c|c|c|c|c|}
\hline & \multirow{2}{*}{$\begin{array}{l}\text { No. of } \\
\text { patients }\end{array}$} & \multicolumn{3}{|c|}{$\begin{array}{c}0-\leqslant 6 \text { months after frozen shoulder } \\
\text { diagnosis }\end{array}$} & \multicolumn{3}{|c|}{$\begin{array}{c}>6 \text { months after frozen shoulder } \\
\text { diagnosis }\end{array}$} \\
\hline & & & ers & SIR & Car & ers & SIR \\
\hline All patients & 29098 & 198 & 143.9 & $1.38(1.19-1.58)$ & 2374 & 2290.4 & $1.04(1.00-1.08)$ \\
\hline Female & 16220 & 103 & 78.3 & $1.31(1.07-1.59)$ & 1332 & 1240.2 & $1.07(1.02-1.13)$ \\
\hline $\begin{array}{l}\text { Age at frozen shoulder diagnosis } \\
\leqslant 39 \text { years } \\
40-49 \text { years } \\
50-59 \text { years } \\
>59 \text { years }\end{array}$ & $\begin{array}{l}3264 \\
7641 \\
10398 \\
7795\end{array}$ & $\begin{array}{r}0 \\
29 \\
101 \\
68\end{array}$ & $\begin{array}{r}0.3 \\
18.0 \\
89.7 \\
35.9\end{array}$ & $\begin{array}{l}-\overline{-} \\
1.61(1.08-2.31) \\
1.13(0.92-1.37) \\
1.90(1.47-2.40)\end{array}$ & $\begin{array}{r}14 \\
402 \\
1528 \\
430\end{array}$ & $\begin{array}{r}7.5 \\
390.2 \\
1507.1 \\
385.5\end{array}$ & $\begin{array}{l}1.86(1.02-3.12) \\
1.03(0.93-1.14) \\
1.01(0.96-1.07) \\
1.12(1.01-1.23)\end{array}$ \\
\hline $\begin{array}{l}\text { Year of frozen shoulder diagnosis } \\
\text { 1995-2004 } \\
\text { 2005-2013 }\end{array}$ & $\begin{array}{l}9782 \\
19316\end{array}$ & $\begin{array}{r}88 \\
110\end{array}$ & $\begin{array}{l}45.1 \\
98.8\end{array}$ & $\begin{array}{l}1.95(1.56-2.40) \\
1.11(0.92-1.34)\end{array}$ & $\begin{array}{r}1583 \\
791\end{array}$ & $\begin{array}{r}1528.2 \\
762.2\end{array}$ & $\begin{array}{l}1.04(0.99-1.09) \\
1.04(0.97-1.11)\end{array}$ \\
\hline COPD-no & 27409 & 183 & 133.1 & $1.38(1.18-1.59)$ & 2227 & 2159.7 & $1.03(0.99-1.07)$ \\
\hline COPD-yes & 1689 & 15 & 10.8 & $1.39(0.78-2.29)$ & 147 & 130.7 & $1.12(0.95-1.32)$ \\
\hline Ml-no & 28335 & 186 & 137.2 & $1.36(1.17-1.57)$ & 2293 & 2203.9 & $1.04(1.00-1.08)$ \\
\hline Ml-yes & 763 & 12 & 6.7 & $1.79(0.92-3.12)$ & 81 & 86.4 & $0.94(0.74-1.16)$ \\
\hline Thyroid/Parkinson's disease-no & 28401 & 195 & 140.0 & $1.39(1.20-1.60)$ & 2328 & 2247.3 & $1.04(0.99-1.08)$ \\
\hline Thyroid/Parkinson's disease-yes & 697 & 3 & 3.9 & $0.76(0.16-2.23)$ & 46 & 43.1 & $1.07(0.78-1.42)$ \\
\hline $\begin{array}{l}\text { Number of hospital visits } \\
<\mathrm{Q} 1 \\
\mathrm{Q} 1-\mathrm{O} 2 \\
\mathrm{Q} 2-\mathrm{Q} 3 \\
>\mathrm{Q} 3\end{array}$ & $\begin{array}{l}7276 \\
7273 \\
7277 \\
7272\end{array}$ & $\begin{array}{r}31 \\
8 \\
19 \\
140\end{array}$ & $\begin{array}{l}30.1 \\
35.2 \\
38.2 \\
40.4\end{array}$ & $\begin{array}{l}1.03(0.70-1.46) \\
0.23(0.10-0.45) \\
0.50(0.30-0.78) \\
3.47(2.92-4.09)\end{array}$ & $\begin{array}{l}502 \\
585 \\
627 \\
660\end{array}$ & $\begin{array}{l}576.8 \\
662.5 \\
596.6 \\
454.5\end{array}$ & $\begin{array}{l}0.87(0.80-0.95) \\
0.88(0.81-0.96) \\
1.05(0.97-1.14) \\
1.45(1.34-1.57)\end{array}$ \\
\hline
\end{tabular}


cancers, the SIR for non-Hodgkin's malignant lymphoma (SIR 1.35, 95\% CI: 1.09-1.66) was increased, while the SIRs for lung and breast cancers were not (Table 2). Among 1516 patients with available data on cancer stage, $69 \%$ were diagnosed with stage I or II cancer during $>6$ months follow-up period.

\section{DISCUSSION}

To the best of our knowledge, this is the first nationwide cohort study to examine cancer risk in frozen shoulder patients. We found a slightly increased risk of any cancer diagnosis during the first 6 months following diagnosis of frozen shoulder, while the absolute 6-month risk was $0.70 \%$, thus, 1 out of 142 patients. In particular, there was an association between frozen shoulder and subsequent diagnoses of the lung cancer, breast cancer, and non-Hodgkin's malignant lymphoma.

Our study helps extend the sparse previous research. On the basis of 60 patients, Gheita et al (2010) reported that musculoskeletal lesions can follow a cancer diagnosis with frozen shoulder occurring in $20 \%$ of patients with solid cancers and $7 \%$ of patients with haematological cancers within a mean follow-up time of 3 years. Wedgwood and Benson (1992) observed seven cases (8\%) of frozen shoulder within 30 days after surgery among 89 patients with modified radical mastectomy. Singh et al (2005) reported frozen shoulder as the only symptom of gallbladder cancer in the case of a 35-year-old woman, suggesting that a skeletal condition may be the initial symptom of a cancer (a marker of occult cancer) rather than a complication of cancer. This is important to consider since cancer in the shoulder can be misdiagnosed as a frozen shoulder (Demaziere and Wiley, 1991; Kim et al, 2011). Furthermore, frozen shoulder is one of the differential diagnoses of a paraneoplastic syndrome, and thereby can represent a marker of progression of the underlying malignancy (Ashour et al, 1997).
A possible mechanism underlying the association between lung cancer and frozen shoulder is direct invasion of the cancer into the shoulder joint or peripheral nerves (Jung et al, 2008; Panagopoulos et al, 2014; Lorkowski et al, 2015). This is supported by our data showing that $72 \%$ of lung cancers were diagnosed at stage III or IV. Direct invasion could occur in particular for apical lung cancer, presenting with rapid onset of clinical symptoms and pleuritic pain due to neurovascular compromise at the level of the superior thoracic aperture (pancoast tumour; Panagopoulos et al, 2014). These symptoms might be mistaken for frozen shoulder. Primary treatment for pain symptoms and frozen shoulder can cause delay in reaching a correct cancer diagnosis, and thus negatively influence prognosis (Sano et al, 2010). Synovial reaction of extraarticular bone and capsular carcinomatosis (Wedgwood and Benson, 1992) also could explain the association between lung and breast cancer and frozen shoulder. Physicians and surgeons should be open to differential diagnoses if initial treatment of a frozen shoulder is ineffective, including the possibility of lung or breast cancer. Increased risk of cancer diagnosis following frozen shoulder could also be due to diagnostic heightening, since SIR was highest for patients with frequent contacts to the hospital. In addition, frozen shoulder patients undergo shoulder radiographs, which also visualise part of the lungs. This might increase the probability of lung cancer detection.

In our study, 29098 persons would have had to be screened in order to find 54 extra cancer cases during the 6 months of followup. The benefits of screening among patients with frozen shoulder, including early diagnosis and improved prognosis, especially for lung and breast cancer, need to be weighed against risks associated with routine screening, such as cost, need for confirmatory tests, and associated anxiety, and stress.

The completeness and positive predictive value of cancer diagnoses in the DCR is 95-98\% (Storm, 1988; Storm et al, 1997). Although we used population-based registry data with virtually complete follow-up, we lacked clinical data on some risk

Table 2. SIRs of selected cancer types in patients with a prior first-time hospital-based diagnosis of frozen shoulder, stratified by follow-up periods, Denmark, 1995-2013

\begin{tabular}{|c|c|c|c|c|c|c|}
\hline \multirow[b]{3}{*}{ Cancer site } & \multicolumn{6}{|c|}{$0-\leqslant 6$ months after frozen shoulder diagnosis $>6$ months after frozen shoulder diagnosis } \\
\hline & \multicolumn{2}{|c|}{ Cancers } & \multirow{2}{*}{$\begin{array}{c}\text { SIR } \\
95 \% \mathrm{Cl}\end{array}$} & \multicolumn{2}{|c|}{ Cancers } & \multirow{2}{*}{$\begin{array}{c}\text { SIR } \\
95 \% \mathrm{Cl}\end{array}$} \\
\hline & $\begin{array}{c}\text { No. } \\
\text { observed }\end{array}$ & $\begin{array}{c}\text { No. } \\
\text { expected }\end{array}$ & & $\begin{array}{l}\text { No. } \\
\text { observed }\end{array}$ & No. expected & \\
\hline Oesophagus & 3 & 1.5 & $2.02(0.42-5.90)$ & 27 & 23.6 & $1.14(0.75-1.67)$ \\
\hline Large intestine including colon rectosigmoid & 6 & 8.1 & $0.74(0.27-1.61)$ & 123 & 136.4 & $0.90(0.75-1.08)$ \\
\hline Rectum & 3 & 4.6 & $0.65(0.13-1.90)$ & 62 & 74.9 & $0.83(0.63-1.06)$ \\
\hline Pancreas & 5 & 2.8 & $1.79(0.58-4.17)$ & 46 & 47.2 & $0.97(0.71-1.30)$ \\
\hline Lung & 30 & 13.7 & $2.19(1.48-3.13)$ & 250 & 223.9 & $1.12(0.98-1.26)$ \\
\hline Breast & 30 & 19.9 & $1.51(1.02-2.15)$ & 305 & 295.0 & $1.03(0.92-1.16)$ \\
\hline Uterus & 3 & 2.9 & $1.04(0.21-3.02)$ & 44 & 47.2 & $0.93(0.68-1.25)$ \\
\hline Prostate & 14 & 11.0 & $1.27(0.70-2.14)$ & 186 & 202.2 & $0.92(0.79-1.06)$ \\
\hline Brain & 3 & 2.6 & $1.17(0.24-3.43)$ & 34 & 35.9 & $0.95(0.66-1.33)$ \\
\hline Non-Hodgkin's malignant lymphoma & 10 & 4.4 & $2.28(1.09-4.20)$ & 94 & 69.4 & $1.35(1.09-1.66)$ \\
\hline $\begin{array}{l}\text { Metastases and non-specified cancer in lymph } \\
\text { nodes }\end{array}$ & 6 & 2.2 & $2.78(1.02-6.06)$ & 35 & 34.0 & $1.03(0.72-1.43)$ \\
\hline
\end{tabular}


factors and on diagnosis, and treatment of frozen shoulder. The validity of the frozen shoulder diagnosis in the DNPR is probably high, because it is not difficult to ascertain, and we excluded lowerquality emergency room diagnoses. However, diagnostic misclassification between frozen shoulder and other conditions, including shoulder impingement and, in rare cases, shoulder cancer, can occur (Rothman, 2002).

In conclusion, we found an association between frozen shoulder and a subsequent risk of cancer diagnosis. Thus, frozen shoulder might be an early predictor of cancer. However, the absolute cumulative risk of cancer is too small to recommend screening of frozen shoulder patients in order to find occult cancer.

\section{CONFLICT OF INTEREST}

The authors declare no conflict of interest.

\section{AUTHOR CONTRIBUTIONS}

HTS was responsible for the study design and concept. HTS, ABP, and EH-P conducted the data analyses. HTS, ABP, EH-P, VE, and MR actively and substantively contributed to the writing of the manuscript, performing literature searches, interpreting data, and providing comments on multiple iterations of the manuscript.

\section{REFERENCES}

Ashour AA, Verschraegen CF, Kudelka AP, Kavanagh JJ (1997) Paraneoplastic syndromes of gynecologic neoplasms. J Clin Oncol 15(3): 1272-1282.

Balch CM, Gershenwald JE, Soong SJ, Thompson JF, Atkins MB, Byrd DR, Buzaid AC, Cochran AJ, Coit DG, Ding S, Eggermont AM, Flaherty KT, Gimotty PA, Kirkwood JM, McMasters KM, Mihm Jr MC, Morton DL, Ross MI, Sober AJ, Sondak VK (2009) Final version of 2009 AJCC melanoma staging and classification. J Clin Oncol 27(36): 6199-6206.

Chang YT, Chang WN, Tsai NW, Cheng KY, Huang CC, Kung CT, Su YJ, Lin WC, Cheng BC, Su CM, Chiang YF, Lu CH (2015) Clinical features associated with frozen Shoulder Syndrome in Parkinson's disease. Parkinsons Dis 2015: 232958.

Cheville AL, Tchou J (2007) Barriers to rehabilitation following surgery for primary breast cancer. J Surg Oncol 95(5): 409-418.

Demaziere A, Wiley AM (1991) Primary chest wall tumor appearing as frozen shoulder. Review and case presentations. J Rheumatol 18(6): 911-914.

Eljabu W, Klinger HM, von KM (2016) Prognostic factors and therapeutic options for treatment of frozen shoulder: a systematic review. Arch Orthop Trauma Surg 136(1): 1-7.

Gheita TA, Ezzat Y, Sayed S, El-Mardenly G, Hammam W (2010) Musculoskeletal manifestations in patients with malignant disease. Clin Rheumatol 29(2): 181-188.

Gjerstorff ML (2011) The Danish Cancer Registry. Scand J Public Health 39(7 Suppl): 42-45.

Huang YP, Fann CY, Chiu YH, Yen MF, Chen LS, Chen HH, Pan SL (2013) Association of diabetes mellitus with the risk of developing adhesive capsulitis of the shoulder: a longitudinal population-based followup study. Arthritis Care Res 65(7): 1197-1202.

Jung YH, Woo SH, Jeon SH, Lee WY, Lim YH, Yoo BH (2008) Right shoulder pain due to metastatic lung cancer: a case report. Korean J Pain 21(2): 164-167.

Kim SY, Jung MW, Kim JM (2011) The shoulder pain due to metastatic breast cancer -a case report. Korean J Pain 24(2): 119-122.

Latham R, Lancaster AD, Covington JF, Pirolo JS, Thomas CS (2001) The association of diabetes and glucose control with surgical-site infections among cardiothoracic surgery patients. Infect Control Hosp Epidemiol 22(10): 607-612.

Lorkowski J, Grzegorowska O, Kotela A, Werynski W, Kotela I (2015) Shoulder ring complaints as a rare first symptom of malignant pleural mesothelioma. Adv Exp Med Biol 852: 5-10.

Panagopoulos N, Leivaditis V, Koletsis E, Prokakis C, Alexopoulos P, Baltayiannis N, Hatzimichalis A, Tsakiridis $\mathrm{K}$, Zarogoulidis $\mathrm{P}$, Zarogoulidis K, Katsikogiannis N, Kougioumtzi I, Machairiotis N, Tsiouda T, Kesisis G, Siminelakis S, Madesis A, Dougenis D (2014) Pancoast tumors: characteristics and preoperative assessment. J Thorac Dis 6(Suppl 1): S108-S115.

Robinson CM, Seah KT, Chee YH, Hindle P, Murray IR (2012) Frozen shoulder. J Bone Joint Surg Br 94(1): 1-9.

Robinson D, Halperin N, Agar G, Alk D, Rami K (2003) Shoulder girdle neoplasms mimicking frozen shoulder syndrome. J Shoulder Elbow Surg 12(5): 451-455.

Rothman KJ (2002) Epidemiology. An Introduction. Oxford University Press. Rothman KJ, Boice JD (1982) Epidemiologic Analysis with a Programmable Calculator, New Edition. Epidemiology Resources, Inc.: Boston, MA, USA.

Sano H, Hatori M, Mineta M, Hosaka M, Itoi E (2010) Tumors masked as frozen shoulders: a retrospective analysis. J Shoulder Elbow Surg 19(2): 262-266.

Schmidt M, Pedersen L, Sorensen HT (2014) The Danish Civil Registration System as a tool in epidemiology. Eur J Epidemiol 29(8): 541-549.

Schmidt M, Schmidt SA, Sandegaard JL, Ehrenstein V, Pedersen L, Sorensen HT (2015) The Danish National Patient Registry: a review of content, data quality, and research potential. Clin Epidemiol 7: 449-490.

Singh A, Singh OP, Goel MM (2005) Frozen shoulder as the initial presentation of gallbladder cancer diagnosed by fine needle aspiration cytology. Acta Cytol 49(3): 345-347.

Storm HH (1988) Completeness of cancer registration in Denmark 1943-1966 and efficacy of record linkage procedures. Int J Epidemiol 17(1): $44-49$.

Storm HH, Michelsen EV, Clemmensen IH, Pihl J (1997) The Danish Cancer Registry-history, content, quality and use. Dan Med Bull 44(5): 535-539.

Wedgwood KR, Benson EA (1992) Non-tumour morbidity and mortality after modified radical mastectomy. Ann R Coll Surg Engl 74(5): 314-317.

Wohlgethan JR (1987) Frozen shoulder in hyperthyroidism. Arthritis Rheum 30(8): 936-939.

Zuckerman JD, Rokito A (2011) Frozen shoulder: a consensus definition. J Shoulder Elbow Surg 20(2): 322-325.

This work is published under the standard license to publish agreement. After 12 months the work will become freely available and the license terms will switch to a Creative Commons AttributionNonCommercial-Share Alike 4.0 Unported License.

Supplementary Information accompanies this paper on British Journal of Cancer website (http://www.nature.com/bjc) 